\title{
Intersetorialidade e os caminhos da desospitalização numa unidade do SUS
}

\author{
Intersectoriality and the paths of dehospitalization in a SUS unit \\ Intersectorialidad y caminos de deshospitalización en una unidad del SUS
}

Recebido: 07/05/2021 | Revisado: 12/05/2021 | Aceito: 12/05/2021 | Publicado: 30/05/2021

Isabelle Guedes dos Santos Bianco

ORCID: https://orcid.org/0000-0001-5553-8682 Pontifícia Universidade Católica do Rio de Janeiro, Brasil

E-mail: bellegds@gmail.com

Nilza Rogéria de Andrade Nunes

ORCID: https://orcid.org/0000-0002-2208-1054 Pontifícia Universidade Católica do Rio de Janeiro, Brasil E-mail: n.rogerianunes@gmail.com

Mariana Setúbal Nassar de Carvalho ORCID: https://orcid.org/0000-0002-0076-6589 Instituto Fernandes Figueira, Brasil Fundação Oswaldo Cruz, Brasil E-mail: msnassar@gmail.com

\begin{abstract}
Resumo
O artigo discute como se constitui o trabalho em rede no processo de desospitalização. Este geralmente envolve usuários com alguma dependência em razão de condições crônicas que se evidenciam quando associadas a determinação social da saúde. A metodologia do estudo foi de natureza qualitativa, na qual utilizamos a observação participante e a entrevista semiestruturada com o setor de desospitalização de um hospital público localizado no município do Rio de Janeiro. Os resultados apontam que o trabalho em rede abarca articulações internas e externas, tendo como principais dificuldades a precarização das políticas públicas, a pessoalidade e as dificuldades de comunicação entre as equipes. Concluímos que há necessidade de se pensar a desospitalização a partir da ótica de políticas públicas que assegurem o cuidado como um direito.
\end{abstract}

Palavras-chave: Colaboração intersetorial; Direito à saúde; Direito ao cuidado de saúde.

\begin{abstract}
This article discusses how networking is constituted in the dehospitalization process. It usually involves users with some condition of dependence due to chronic issues that are evident when associated with social expressions. The study methodology was based on qualitative nature, in which participant observation was used together with semi-structured interviews with the dehospitalization sector of a public hospital located in the city of Rio de Janeiro. The findings show that the networking encompasses both internal and external articulations, having as its main challenges the precariousness of public policies, the personal relations and the difficulties of communication among teams. We conclude that there is a need to think about dehospitalization from the perspective of public policies and that ensure care as a right.
\end{abstract}

Keywords: Intersectoral collaboration; Right to health; Right to health care.

\section{Resumen}

El artículo analiza cómo se constituye el trabajo en red en el proceso de deshospitalización. Suele involucrar a usuarios con cierta dependencia debido a condiciones crónicas que se manifiestan cuando se asocia con la determinación social de la salud.

La metodología de estudio fue de naturaleza cualitativa, en la que se utilizó observación participante y entrevistas semiestructuradas con el sector de deshospitalización de un hospital público ubicado en la ciudad de Río de Janeiro. Los resultados señalan que el trabajo en red incluye articulaciones internas y externas, teniendo como principales dificultades la precariedad de las políticas públicas, la personalidad y las dificultades de comunicación entre los equipos. Concluimos que es necesario pensar en la deshospitalización desde la perspectiva de las políticas públicas que aseguren el cuidado como un derecho.

Palabras clave: Colaboración intersectorial; Derecho a la salud; Derecho a la asistencia sanitaria.

\section{Introdução}

A desospitalização configura-se como um processo que tensiona questões de ordem social, biológica e econômica (Rocha, 2016). Esta articula-se com a determinação social da saúde, que engloba de maneira mais ampla a realidade social, a 
partir de mediações entre a realidade fragmentada e a totalidade social (Rocha \& Davi, 2014), compreendendo o direito à saúde em sua integralidade, uma vez que ter saúde implica em uma série de determinações que estão para além da simples ausência de doenças (Organização Mundial de Saúde, 1946; Nunes, Rocha \& Fernandes, 2019). De maneira geral, os usuários envolvidos nesse processo possuem alguma condição de dependência em razão de condições crônicas que se evidenciam quando associada à determinação social da saúde.

O trabalho na desospitalização deve ter como objetivo a integralidade da atenção, que demanda uma articulação dos serviços de saúde a uma rede muito mais complexa, composta tanto por outros serviços de saúde, como por outras instituições não necessariamente desse setor (Cecílio, 2001); além da possibilidade que o usuário saia da instituição com condições dignas de cuidado. Nesse sentido, a desospitalização, ao nosso ver, não deve se relacionar com uma alta precoce, mas com uma alta segura e responsável ${ }^{1}$. Esta deve ser trabalhada e planejada pela equipe, no sentido buscar coletivamente respostas para a demanda do usuário por condições dignas de alta hospitalar e da requisição institucional pela desocupação do leito com a garantia de não reincidência do problema que levou o usuário à internação (Vasconcelos, 2015, p. 532).

A transição demográfica e epidemiológica observada nas últimas três décadas demarcam a centralidade do cuidado em seu aspecto integral. Desse modo, o Brasil vive ao mesmo tempo um período acelerado de envelhecimento demográfico com importantes implicações para indivíduos, famílias e sociedade (Instituto Brasileiro de Geografia e Estatística, 2015, p.141), e uma situação de transição epidemiológica, caracterizada pela queda relativa das condições agudas e pelo aumento relativo das condições crônicas (Mendes, 2012). Ressaltamos, a partir da realidade brasileira, que esse processo é heterogêneo, tendo em vista as desigualdades em saúde; assim, diferenças geográficas, de gênero e de gerações acentuam uma grande diversidade de aspectos desse processo de transição (Moreira \& Goldani, 2010).

Segundo dados da Organização Mundial de Saúde (OMS), de 2003, as chamadas Doenças Crônicas Não Transmissíveis (DCNT) são responsáveis por mais de $70 \%$ de todas as mortes no mundo (o equivalente a 41 milhões de pessoas). Na busca por um modelo de atenção à saúde que pudesse, ao mesmo tempo dialogar com este novo perfil epidemiológico e também fosse voltado para os preceitos do Sistema Único de Saúde (SUS), Eugênio Vilaça Mendes elaborou estratégias de gestão do cuidado, intencionando o atendimento das necessidades de saúde da população atendida. O denominado Modelo da Pirâmide de Riscos define as estratégias de intervenção em autocuidado e em cuidado profissional (Mendes, 2019), como mostra a figura abaixo:

Figura 1. Modelo da Pirâmide de Riscos.

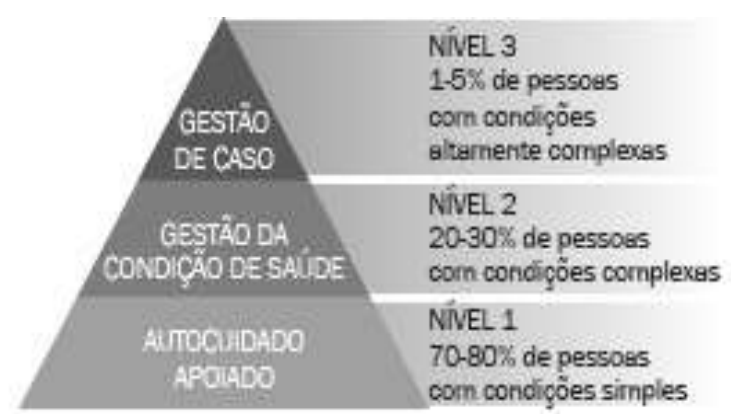

Fonte: Department of Heath (2005a).

Fonte: Mendes (2019).

\footnotetext{
1 Ver a Política Nacional de Atenção Hospitalar (2016).
} 
Tais estratégias baseadas na gestão dos riscos dialogam com os fluxos da linha de cuidado, que pode ser compreendida como uma imagem pensada para expressar os fluxos assistenciais seguros e garantidos ao usuário, no sentido de atender às suas necessidades de saúde (Franco et al., 2011). Esta centra-se em atender às necessidades do usuário, o que ultrapassa o sistema de saúde, mas perpassa diversos serviços públicos, podendo ser trabalhada em qualquer unidade que o usuário tiver acesso. Quando falamos do contexto hospitalar, é primordial a criação e estabilização de linhas que rompam os limites do hospital e se transversalizem por outros serviços, visando à integralidade do cuidado (Cecílio \& Merhy, 2007, p. 211).

No entanto, as necessidades de saúde relacionadas a esse perfil de adoecimento da população sofrem os impactos do desfinanciamento na política de saúde, associado à contrarreforma neoliberal, que vem tomando maiores proporções, prejudicando diretamente a efetivação do direito à saúde. Um dos desmontes recentes mais devastadores é a Proposta de Emenda Constitucional (PEC) 241, que congela os gastos por vinte anos das políticas sociais, dentre elas, a política de saúde. Concordamos com Vieira e Benevides (2016, p. 08), quando os autores apontam que o congelamento não leva em conta as transformações demográficas e epidemiológicas em curso no país, tampouco a desigualdade estrutural de sua formação social.

A saúde padece com a redução de recursos em consequência das chamadas "reformas constitucionais" que vêm sendo perpetradas no Brasil desde o início da década de 1990, sob o argumento de que a Constituição Cidadã de 1988 seria o principal empecilho ao processo de "modernização" e "abertura" do país (Soares, 2000, p. 17). Nesse sentido, como consequência dessa contrarreforma (Behring, 2011), o Estado se desresponsabiliza de suas obrigações com a sociedade civil e sua atuação passa a ser focalizada e minimalista, sem objetivar a ampliação de direitos sociais.

No contexto da saúde, a implementação do SUS e das leis que o regulamentaram no início dos anos 1990 ocorreram na antessala da virada neoliberal, sendo, na prática, afetadas pela contrarreforma do Estado antes de sua consolidação (Cislaghi, 2018, p. 11). A saúde passa a ser tensionada pela disputa de dois projetos (Bravo, 2006): o projeto sanitário, que representa a Reforma Sanitária em defesa de uma saúde universal, integral e de qualidade e o projeto privatista, que é aliado ao projeto neoliberal, que intenciona transformar a saúde, assim como todas as políticas sociais, como fonte de lucro. É importante ressaltar que a partir dos anos 2000 tem-se a proposição de flexibilizar a Reforma Sanitária com o chamado SUS possível, que passa a ser orientado por uma terceira via; ou seja, não há preocupação com a superação do capitalismo (Bravo, 2013).

Podemos afirmar que o setor de saúde tem se constituído como um espaço de grande interesse de grupos econômicos em sua busca por lucros e em seu movimento para impor a lógica privada nos espaços públicos (Bravo, Pelaez \& Pinheiro, 2018, p. 11). Tais interesses influenciam na desospitalização, que tem sido associada também a uma ferramenta de gestão hospitalar que propicia a rotatividade dos leitos. Vecina Neto e Malik (2007) destacam a existência de uma série de iniciativas voltadas para a redução da utilização de leitos, o que à primeira vista, parecem um contrassenso, pois os hospitais vivem de "vender" leitos a serem ocupados. Um estudo apresentado pela revista Visão Saúde (2018, p. 51), apresenta a desospitalização como uma possibilidade de melhoria na gestão hospitalar, pois as internações hospitalares custam quase R $\$ 50$ bilhões aos planos de saúde.

Quando a desospitalização é trabalhada unicamente na perspectiva de racionalização dos custos e da liberação de leitos, vai no sentido oposto à garantia de direitos sociais. É o que mostra a pesquisa de Cunha e Morais (2006) sobre a prestação de serviço de atenção domiciliar por meio de operadora privada. As autoras destacam a existência da alta hospitalar precoce e a responsabilização da família pelos cuidados.

A responsabilização das famílias é uma questão de extrema relevância na discussão sobre a desospitalização, uma vez que é necessário pensarmos como será prestado o cuidado no momento da alta, fazendo as mediações que o localizam dentro na sociedade capitalista em que vivemos, em um contexto neoliberal (Wise, Dal Prá \& Mioto, 2017). Isso posto, podemos elencar duas perspectivas: a que compreende a família como a provedora de bem-estar, denominada familiarista, e a da social-democracia, que propõe a oferta de serviços públicos universais e assim ameniza os custos enfrentados pelas famílias (Mioto \& Dal Prá, 2015). 
Dessa maneira, as famílias são incumbidas do cuidado sem que o Estado lhe forneça subsídios para tal. Ao mesmo tempo, a ausência deste se reflete na diminuição dos serviços públicos, como por exemplo: internação hospitalar, centros-dia para atendimento de idosos e de pessoas com deficiência, centros de convivência, instituições de longa permanência, entre outros, que deveriam prover o cuidado a diversos segmentos da população (Wise, Dal Prá \& Mioto, 2017).

É importante refletir também sobre a sobrecarga das mulheres que em sua maioria serão as principais — e em muitos casos as únicas - responsáveis pelo cuidado. Desse modo, na sociedade contemporânea, evidencia-se a atribuição feminina na reprodução dos comportamentos que devem ser ensinados e reproduzidos pelas mulheres, reduzindo completamente a sua essência (Passos, 2017) e se constituindo como uma prática social que se ancora na divisão sexual do trabalho e objetiva atender às necessidades humanas concretas, mas também emocionais e psicológicas (Marcondes, 2013).

A nossa compreensão de que a responsabilidade da proteção social não está restrita às famílias e, portanto, a solução extrapola as suas possibilidades individuais (Mioto, 2010, p. 172), nos possibilita fazer uma conexão com as potencialidades da existência da rede como forma de garantia de direitos e corresponsabilização por parte do Estado acerca do cuidado, objetivando uma divisão justa de responsabilidades.

\section{Metodologia}

Trata-se de pesquisa qualitativa, realizada no ano de 2019, com base nos seguintes procedimentos de investigação: entrevista semiestruturada e observação participante, em um período de três meses, no qual foi possível acompanhar a rotina do serviço, sendo aprovada em Comitê de Ética em Pesquisa da instituição ${ }^{2}$. A escolha da abordagem qualitativa relaciona-se ao entendimento de que ela trabalha com o universo de significados, motivos, aspirações, crenças, valores e atitudes, o que corresponde a um espaço mais profundo das relações que não podem ser reduzidas à operacionalização de variáveis (Minayo, 2002, p. 22).

A pergunta que norteou a pesquisa de campo foi a seguinte: como se constitui o trabalho em rede no processo de desospitalização de um hospital federal de referência para pacientes de média e alta complexidade do Rio de Janeiro? Foram entrevistados individualmente sete profissionais (assistente social, enfermeiros, psicóloga, técnicas de enfermagem e técnica em assuntos educacionais) que compõem a equipe.

\section{Resultados e Discussão}

O Programa de Desospitalização que foi cenário da pesquisa é composto por três macroprocessos ${ }^{3}$, explicitados pelo participante 3:

O primeiro é captar a família para esse processo (...) O segundo é rede de atenção à saúde, que é voltado para atender as instituições que vão acolher e não a instituição familiar ou comunitária, mas as instituições estatais. E o terceiro que tem a ver com construção de conhecimento sobre saúde (Participante 3).

Percebe-se que o perfil dos usuários admitidos pelo programa de desospitalização é composto por idosos e pessoas com condições crônicas de saúde. Os critérios de admissão no Programa eram:

\footnotetext{
${ }^{2}$ CAAE: 15755019.9 .0000 .5253

${ }^{3}$ Do ponto de vista da gestão hospitalar, macroprocessos são os que envolvem mais de uma função na estrutura organizacional e possuem impacto significativo nas instituições.
} 
“(...) Oncológico, idoso, acamado e longa permanência, cujo tempo definido pela equipe é de 15 dias” (Participante 5).

O perfil selecionado não é uma escolha fortuita, mas parte do entendimento de que vivenciamos no Brasil e no mundo uma transição demográfica e epidemiológica que vem modificando nas duas últimas três décadas o perfil de morbimortalidade no país, bem como das hospitalizações, tanto no SUS quanto na saúde suplementar. O aumento da expectativa de vida, o sucesso das campanhas de imunopreveníveis, aliado ao avanço da biomedicina e à melhora em indicadores sociais importantes fizeram com que o perfil de adoecimento crônico aumentasse de forma significativa no conjunto da população, exigindo uma reorganização dos serviços de saúde e de novas estratégias relacionadas ao cuidado e às políticas públicas voltadas para essa população (Carvalho, 2019).

Em consonância com esse fato, a Organização Mundial de Saúde definiu as condições crônicas de saúde como: “problemas que requerem gerenciamento contínuo por um período de vários anos ou décadas e abarcam uma categoria ampla de agravos" (OMS, 2003). Salientamos a relação entre as condições crônicas e a determinação social da saúde. Esta vai de encontro a uma perspectiva que entende os fatores de risco como estilos de vida e escolhas individuais. Nesse sentido, o aumento da prevalência das condições crônicas associa-se à determinação social da saúde, na medida que a população mais pobre a que paga o maior tributo em termos de saúde, acumulando a carga de maior frequência de distribuição de doenças, sejam estas de origem infecciosa, sejam crônico-degenerativas, entre outras (Escorel, 2009). As Doenças Crônicas Não Transmissíveis aprofundam as iniquidades sociais e constituem um obstáculo para os esforços na luta contra a pobreza e desigualdade (Malta, et.al, 2014).

Este novo cenário ressalta a importância da reflexão sobre quem presta estes cuidados. No período de observação no campo, foi notável a predominância de mulheres como acompanhantes e cuidadoras dos usuários do Programa de Desospitalização, corroborando com a ideia do cuidado enquanto uma necessidade ontológica do ser social (Passos, 2018), uma vez que os usuários da desospitalização necessitam que alguém exerça suas atividades ontológicas primárias, e esse papel de cuidado é atribuído socialmente às mulheres.

Outro aspecto relevante está relacionado à denominada "intersetorialidade". A referida equipe pontuou três questões principais no que diz respeito às dificuldades no trabalho em rede: a precarização da infraestrutura dos equipamentos da rede, a pessoalidade presente em grande parte desse trabalho e a dificuldade de comunicação entre as equipes/instituições. Como destaca uma participante:

"Acho que o maior desafio nosso é lidar com a precariedade da rede externa. A gente lida bem aqui dentro do hospital, mas a rede externa, a precariedade, está difícil. Principalmente dos outros municípios que não tem nem sequer telefone" (Participante 4).

Temos compreensão de que o campo nos traz uma possibilidade de novas revelações (Cruz Neto, 2002) sobre a temática estudada. Desse modo, destacamos que anteriormente à entrada no campo e da análise dos dados das entrevistas, a percepção que se tinha do trabalho em rede era de que este estava totalmente voltado ao âmbito externo, ou seja, para fora da instituição. No entanto, no período de observação participante e durante as entrevistas, a noção de rede interna foi bastante enfatizada pela equipe, o que nos leva a afirmar que o trabalho em rede se configura em dois âmbitos: a rede interna e a externa, que estão imbricadas. As redes internas, na verdade, estão amplamente articuladas às redes externas e o objetivo é proporcionar a integralidade do cuidado à população usuária, seja dentro do hospital — na tentativa de romper com a fragmentação do cuidado — ou fora, no sentido de sua continuidade. 
O desmonte do Estado brasileiro tem levado a uma crescente desresponsabilização do governo federal das suas atribuições no terreno social (Soares, 2000). Isso torna inviável a materialização do ideário da reforma sanitária — que colocou em questão o paradigma vigente que entendia a saúde como ausência de doença - e da própria efetivação do SUS enquanto um sistema universal e integral. Dessa forma, apesar de todos terem direito à saúde, nem todos conseguem atendimento em virtude não só da precariedade dos serviços, mas também da qualidade destes, acarretando impactos direto no trabalho, gestão e cuidado em saúde (Castro et al., 2018, p. 68). Outra dificuldade relatada é o caráter de pessoalidade assumido no trabalho em rede:

O problema é que a rede muda muito. A gente faz um trabalho que é muito pessoal, a gente tem uma dificuldade muito grande de falar com instituições. A gente acaba falando com as pessoas que estão nessas instituições e as pessoas mudam, elas migram para outra função e essa rede está sempre se reconstruindo (Participante 2).

Os desafios referentes à pessoalidade conversam com a análise de Akerman et al. (2014), que afirmam que a maioria dos estudos aponta para o fato de uma articulação intersetorial em rede ter sido implementada predominantemente de forma pontual e fragmentada. Essa pessoalidade, ao nosso ver, pode acarretar duas importantes consequências: a primeira é em relação a descontinuidade no trabalho sem que haja estabelecimento de pactuações entre as instituições, prejudicando a continuidade do cuidado. A segunda refere-se a uma possível associação, por parte dos serviços existentes na rede, com questões políticas, que pode fazer com que o acesso a determinado serviço da rede seja levado para o campo do assistencialismo e não como um direito. Concordamos com Costa (2010) quando o autor indica que para superar o voluntariado, a benemerência e o assistencialismo na construção de redes deve-se constituir uma articulação que, no mínimo, combine dois movimentos:

1) Forçar o Estado brasileiro a assumir o seu papel na garantia da seguridade e proteção social e não de transferência de suas responsabilidades para a sociedade. 2) Agregar saberes e poderes para fortalecer movimentos organizativos e lutas em defesa de direitos e da solidariedade classista, superando o patamar das articulações calcadas no voluntariado e na solidariedade cristã (Costa, 2010, p. 214).

Entendemos que a dificuldade na comunicação está atrelada justamente à pessoalidade e a fragmentação, além da precarização das políticas sociais. Akerman et al. (2014, p. 4296) indicam que a existência da "comunicação imperfeita" entre políticas/atores talvez ocorra também na interface entre as respostas formuladas por governos e as necessidades sentidas/percebidas pelos cidadãos. Nesse sentido, apesar de a rede ser constituída por pessoas — o que envolve uma linguagem de vínculos, das relações sociais entre organizações que interagem mediadas por atores sociais que buscam entender de maneira compartilhada a realidade social — é importante que os objetivos sejam pensados e construídos coletivamente (Junqueira, 2000).

Outra pergunta realizada à equipe, era se havia contrarreferência dos casos encaminhados para a rede. Oficialmente, não há um sistema de referência e contrarreferência. Um dos participantes explica:

(...) Quando a gente faz a pactuação com a rede, a gente liga para a rede para dar o passo a passo do paciente: "Oh, tem previsão de alta... sai essa semana... já está em casa”. Ou a gente liga para rede para saber: "já fez a visita? A família já foi aí?" Que é na continuidade. São raras as vezes quando a rede nos procura (Participante 3).

O não funcionamento, de fato, do sistema de referência e contrarreferência não é uma particularidade dessa instituição hospitalar, mas, como salientam Merhy e Cecílio (2007), é um sistema que ainda pouco funciona com a racionalidade pretendida. 
No entanto, é um mecanismo importante de pactuação entre as instituições, no que se refere à responsabilização das equipes sobre a continuidade do cuidado. Compartilhando dessa compreensão, o serviço de desospitalização implementou um processo chamado follow up e, a partir dele, é obtido o conhecimento da continuidade do cuidado. O participante 7 explica que:

Esse follow up é feito pela equipe. No final do processo, a pessoa foi para casa e a gente dá mais ou menos uns 15 dias para a pessoa poder se estabilizar em casa. É feita uma ligação de retorno para saber se foi feito, se a pessoa deu entrada. Se a pessoa diz que deu entrada, a gente retorna para a unidade de referência e pergunta se a visitação foi feita. Aí, geralmente quando não é feita, eles marcam, eles agendam (Participante 7).

A equipe realiza dois tipos de follow up: da rede domiciliar, no qual se faz contato com o usuário/familiares para saber como está o cuidado, baseado na escala $\mathrm{KPS}^{4}$, e o follow up da rede de serviços, em que é contatado a rede para verificar se já foi realizado o atendimento ao usuário. Dessa forma, mediante a ausência de um mecanismo formalizado de referência e contrarreferência, um dos participantes afirma que, muitas vezes, o retorno sobre o acesso a determinado serviço da rede fica a cargo do próprio familiar. Caso o mesmo, via follow up, relate para a equipe dificuldades em relação ao cuidado, o participante 5 afirma que:

“(...) a gente pode avaliar a necessidade de ir lá ver a situação para a gente poder dar um reforço na orientação diante da realidade que está posta" (Participante 5).

Esse aspecto demonstra a responsabilização que a equipe tem no momento da alta, além da construção do vínculo que se inicia quando o usuário é admitido no programa de desospitalização. A respeito da construção do vínculo entre a equipe e os familiares, este é iniciado ainda na internação quando o usuário começa a ser acompanhado pelo programa de desospitalização. Acreditamos que essa responsabilização da equipe é um dos fatores que faz com que a família tenha mais segurança em levar o usuário para casa no momento da alta. O compartilhamento da responsabilidade pela equipe, no que se refere a continuidade do cuidado, é demonstrado nas seguintes falas: “A paciente só vai receber alta quando a gente conseguir acessar essa rede” (Notas de campo, 2019); "Usuário: Vocês me deram uma direção. Profissional: Qualquer dificuldade que tiver na clínica da família, liga para a gente que a gente fala com eles" (Notas de campo, 2019).

No entanto, dado o contexto de desigualdade social em que vivemos, de acordo com dados da Oxfam (2018), o Brasil ocupa a nona posição de mais desigual do mundo e é muito comum que as famílias que acessam o SUS não apresentem condições de continuar o cuidado de seu familiar. Ao mesmo tempo em que o Estado se ausenta, as famílias são cobradas a dar proteção aos seus membros mesmo que sejam insuficientes as ações destinadas a elas por parte das políticas sociais (Nogueira \& Monteiro, 2014). Destacamos a fala da participante 2:

Se a gente entender que o melhor para o paciente é estar aqui, a gente consegue bancar. A gente consegue, inclusive ajudar a equipe bancar isso, a gente consegue ajudar a família. A ideia não é dar alta, a ideia é desospitalizar. Se não vai ser possível desospitalizar, a gente não vai fazer o movimento da alta, entendeu? (Participante 2).

A resposta acima nos remete a duas questões importantes. A primeira é que ela não reproduz a lógica da responsabilização da família pelo cuidado, o que vai ao encontro de nosso entendimento exposto até aqui. A segunda questão é

${ }^{4}$ Escala de Performance de Karnofsky, através dela é possível avaliar a capacidade do paciente em realizar as atividades cotidianas. 
em relação ao entendimento do que é a desospitalização, no qual envolve diversos aspectos de articulação em rede e a garantia da continuidade do cuidado, sendo diferente e muito além da alta hospitalar.

Ressaltamos a importância do trabalho interdisciplinar ${ }^{5}$, tendo em vista que o enfrentamento da complexidade dos problemas de saúde da população requer que as várias categorias profissionais trabalhem em conjunto, a partir da integração dos campos de conhecimento acumulados nas diversas profissões e também do saber da comunidade (Leite \& Veloso, 2008, p. 379). Não desconsideramos, portanto, os muitos desafios para a sua efetivação no cotidiano dos serviços de saúde. Nestes, temos um trabalho coletivo que é permeado por tensões e características próprias da área, mas influenciadas pela forma como o trabalho vem sendo desenvolvido na sociedade capitalista (Matos, 2017, p. 42).

Dito isso, as falas e direcionamentos dos profissionais do setor de desospitalização nos mostram que muitos são os desafios inerentes ao contexto de sucateamento e privatização da saúde pública, mas que há caminhos de resistência e sendo possível orientar o trabalho, na desospitalização, para uma perspectiva vinculada à garantia de direitos.

\section{Articulação intersetorial em tempos de contrarreforma}

O trabalho em rede é indispensável à desospitalização. Portanto, não há como pensar esse processo descolado de uma rede composta por serviços públicos que seja corresponsável pelo cuidado do usuário. As redes podem ser entendidas como uma forma de organização (Martinho, 2003) de caráter estratégico, uma vez que articula intencionalmente pessoas e grupos e ajuda os atores e agentes sociais a potencializarem suas iniciativas para promover o desenvolvimento pessoal e social (Gonçalves \& Guará, 2010, p. 14).

Assim como Martinho (2003), Gonçalves e Guará (2010), também entendem a rede como uma forma de organização. No entanto, os autores a percebem como uma organização estratégica, uma vez que articula intencionalmente pessoas e grupos e ajuda os atores e agentes sociais a potencializarem suas iniciativas para promover o desenvolvimento pessoal e social (Gonçalves \& Guará, 2010, p. 14).

Outros autores (Junqueira, 2000, Avelar \& Malfitano, 2018) irão trabalhar, principalmente, com a ideia de rede social. Para Avelar e Malfitano (2018), a rede social é formada por sujeitos que, por meio de suas ligações interpessoais, permitem a transmissão de recursos. Já para Junqueira (2000), a rede social é composta por um misto de pessoas e organizações que se relacionam com o intuito de responder demandas e necessidades da população de maneira integrada, mas respeitando o saber e a autonomia de cada membro (Junqueira, 2000, p. 40).

Especificamente no campo da saúde, temos um modelo importante denominado de Redes de Atenção à Saúde (RAS) ${ }^{6}$, que são organizações poliárquicas de conjuntos de serviços de saúde, vinculados entre si por uma missão única, por objetivos comuns e por uma ação cooperativa e interdependente, que permitem ofertar uma atenção contínua e integral a determinada população, coordenada pela APS (Mendes, 2012, p. 47). No entanto, salientamos que nosso interesse no debate sobre o trabalho em rede ultrapassa a focalização na RAS, expandindo-se para a rede de serviços em uma dimensão intersetorialidade, uma vez que as necessidades tendem a sair do escopo da saúde. Ademais, Partimos da ideia de que se o processo de desospitalização for trabalhado sem que seja pensado na organização da rede e sem que haja a garantia do acesso aos serviços que a compõem, poderá cair em uma perspectiva de responsabilização das famílias

5 Os serviços de saúde (nos diferentes níveis de complexidade) geralmente possuem equipes multiprofissionais que são compostas por diferentes profissionais (assistentes sociais, farmacêuticos, psicológicos, fisioterapeutas, etc.). Contudo, a existência de uma equipe multiprofissional não necessariamente constitui um trabalho interdisciplinar, pois a cultura hospitalocêntrica hospitalar tende a fazer com que cada profissional realize suas atribuições separadamente e não haja troca entre a equipe.

$6 \mathrm{O}$ autor elenca que uma população e as regiões de saúde, uma estrutura operacional e um modelo de atenção à saúde são elementos constitutivos da RAS. Ver mais em Mendes (2012). 
Conceitualmente a intersetorialidade é um termo polissêmico (Akerman et al., 2014; Carmo \& Guizardi, 2017), que tem ocupado um lugar central na agenda contemporânea da política social em razão da complexidade que cerca a questão social hoje, traduzida notadamente no agravamento da pobreza e das desigualdades sociais (Monnerat \& Souza, 2014, p.41). Nesse seguimento, identifica-se dois campos em que a intersetorialidade é bastante discutida: da administração e da saúde coletiva. Monnerat e Souza (2014) apontam que no primeiro prevalece a abordagem que enfatiza a preocupação com a questão da otimização de recursos humanos e financeiros. Já no campo da saúde coletiva, tem prevalecido a concepção da OMS, no qual compreende a intersetorialidade como uma articulação de ações de vários setores para alcançar melhores resultados (Monnerat \& Souza, 2014, pp. 42-43).

Muito além da polissemia do termo, Akerman et al. (2014) indicam que, apesar de a intersetorialidade ser bastante ressaltada no campo da saúde coletiva, ainda há um vazio teórico. Carmo e Guizardi (2017) parecem endossar essa ideia quando destacam, como resultado de uma pesquisa sobre a intersetorialidade entre a política de saúde e assistência social, que há uma restrita produção acadêmica sobre a questão da intersetorialidade no país nos últimos treze anos. Em vista disso, Akerman et al. (2014, p.4294) enxerga que há a presença de um ativismo intersetorial que ainda não se funda numa práxis que tenha potência criativa suficiente para influenciar novas arquitetura de governança das políticas públicas.

Concordamos com Junqueira (2000) quando o autor destaca que a intersetorialidade incorpora a ideia de integração, de território, de equidade; enfim, dos direitos sociais. Portanto, supõe a implementação de ações integradas e a superação da fragmentação da atenção às necessidades sociais da população (Yazbek, 2014, p. 98).

Na verdade, uma questão importante a ser destacada e que muito clarifica essa dificuldade com as ações intersetoriais, perpassa pela forma como se constitui a estrutura da sociedade em que vivemos. Essa fragmentação é própria do capitalismo monopolista, uma vez que a política social se constitui necessariamente em políticas sociais: as sequelas da "questão social" são recortadas como problemáticas particulares (o desemprego, a fome, a carência habitacional, o acidente de trabalho, a falta de escolas, a incapacidade física etc.) (Netto, 2005, p. 28).

Assim, consideramos imprescindível deixar claro que, apesar dos limites da sociedade capitalista em que vivemos, nossa compreensão sobre significado de intersetorialidade está atrelado à dimensão da efetivação dos direitos sociais de maneira ampliada. Desse modo, concordamos com Junqueira (2000) quando destaca que a intersetorialidade incorpora a ideia de integração, de território, de equidade, enfim, dos direitos sociais. Portanto, supõe a implementação de ações integradas e a superação da fragmentação da atenção às necessidades sociais da população (Yazbek, 2014, p. 98). Nesse sentido, estamos convictos de que a intersetorialidade não pode resumir somente a articulação dos serviços sociais. Esse ponto é reforçado por Bronzo (2007), que refere que para a superação de forma sustentável das situações de exclusão, deve- se desenvolver um conjunto de ações diferenciadas, intersetorialmente articuladas, que exigirá mais do que uma simples conexão ou agregação de setores.

Diante do contexto de desmonte das políticas públicas, trabalhar em rede torna-se não só um desafio, mas pressupõe uma compreensão coletiva das demandas da população usuária, de maneira que ocupem as agendas públicas. A continuidade do cuidado em caráter integral só pode ser efetivada mediante a superação de sua fragmentação, o que leva à necessidade de ações interdisciplinares e intersetoriais. Então, reiteramos o nosso prisma de que a desospitalização deve ter como parâmetro o trabalho em rede, a alta hospitalar responsável com condições dignas e, portanto, associado à existência de uma rede de serviços que possibilite a efetivação do direito à integralidade do cuidado.

Nesse sentido, partimos da ideia de que o cuidado que é posto como aspecto central no processo de desospitalização, pode ser pensado na perspectiva do direito. Wise, Dal Prá e Mioto (2017, p. 02), enfatizam que em muitos países há avanços legislativos que direcionam para o reconhecimento do cuidado como um direito e da necessidade de se pensar de modo mais equitativo a responsabilidade do cuidado, tanto no interior da família como entre as instituições públicas. Na visão de Dighiero "el derecho al cuidado, debe ser considerado en el sentido de un derecho universal de toda la ciudadanía, desde la doble 
circunstancia de personas que precisan cuidados y que cuidan, es decir, desde el derecho a dar y a recibir cuidados" (2015, p. 11).

Ao ser encarado como uma questão coletiva, o cuidado sai do âmbito familiar como seu lócus central, tendo potencialidades tanto para garantir uma maior igualdade a quem necessita receber os cuidados, como poderá contribuir para uma maior autonomia das mulheres que têm essa tarefa de cuidar, como socialmente atribuído a elas. Entendemos que o Estado deve garantir o funcionamento da rede de serviços para que as famílias sejam apoiadas na provisão do cuidado.

\section{Conclusão}

As transições demográficas e epidemiológicas colocam como bojo central a necessidade do cuidado em sua dimensão integral, fazendo com que a demanda de desospitalização ganhe cada vez mais espaço nas instituições hospitalares. A desospitalização deve ser trabalhada na perspectiva do direito a uma alta com condições dignas, o que muitas vezes implica no acesso a diversos direitos sociais - como habitação, transporte e saneamento básico - para continuar o cuidado que necessita. No entanto, a garantia desse cuidado é permeada por dificuldades diante de um cenário de desfinanciamento do Estado nas políticas públicas, em virtude dos direcionamentos neoliberais que acentuam a precarização da rede de serviços existente e, assim, impede que o usuário tenha acesso aos seus direitos, tendendo ao direcionamento da responsabilidade às famílias pelo cuidado dos usuários que estejam nessa condição.

As conclusões indicam que o trabalho em rede se configura em dois âmbitos: redes internas e externas. Ambas estão amplamente articuladas, com o objetivo de proporcionar a integralidade do cuidado à população usuária, seja dentro do hospital, na tentativa de romper com a fragmentação do cuidado, ou fora, no sentido de sua continuidade.

Neste sentido, apontam-se três principais desafios: a precarização da rede de serviços, a pessoalidade e a dificuldade de comunicação entre as equipes. Essas dificuldades dialogam com os nossos pressupostos neste trabalho, que indicam que a precarização das políticas públicas é um dos fatores que impede a articulação em rede, fazendo com que a população usuária não tenha acesso aos seus direitos, bem como a questão da articulação intersetorial, que ainda funciona de forma pontual e fragmentada (Akerman et al., 2014).

Acreditamos que essa pessoalidade está associada ao fato de que o mecanismo de referência e contrarreferência tem pouca efetividade ou não funciona no cotidiano dos serviços de saúde. Isso foi confirmado nas falas da equipe que referiram que formalmente não há contrarreferência dos casos encaminhados para a rede.

Pela observação dos dados analisados, pudemos refletir que apesar da conjuntura de retrocessos em relação aos direitos sociais é possível trabalhar a desospitalização em um hospital federal do Rio de Janeiro no sentido da garantia de direitos, e que a desospitalização pode contribuir, de fato, para assegurar uma alta hospitalar com condições dignas. Assim, deve-se buscar, com a desospitalização, visualizar o usuário enquanto sujeito de direitos, no qual as condições e demandas colocadas pelas famílias necessitam de mediações com o campo macropolítico. É necessário que se busquem estratégias coletivas para a desospitalização e que a mesma ocupe agenda pública. Aliado a isso, destacamos a importância da sistematização dos dados no cotidiano para que possa auxiliar a construção de conhecimento e proporcionar reflexões sobre os dados produzidos no dia a dia.

É importante destacar que, ainda que seja evidente o protagonismo da família na continuidade do cuidado dos usuários desospitalizados, não se observou nenhum discurso da equipe e/ou reprodução de uma lógica que responsabiliza unicamente as famílias pelo cuidado. Assim, é reforçado pela equipe citada o direito e a corresponsabilização do Estado.

Por fim, esperamos que estudos futuros sejam desenvolvidos, tendo em vista a relevância da temática no cotidiano dos serviços de saúde. Nesse sentido, como sugestões apontamos para a investigação a respeito da interlocução entre programas de desospitalização existentes discutindo suas potencialidades. 


\section{Agradecimentos}

O presente trabalho foi realizado com apoio da Coordenação de Aperfeiçoamento de Pessoal de Nível Superior - Brasil (CAPES)

- Código de Financiamento 001.

\section{Referências}

Akerman, M., Franco de Sá, R., Moyses, S., Rezende, R., \& Rocha, D. (2014). Intersetorialidade? IntersetorialidadeS! Ciência \& Saúde Coletiva, 19(11), 42914300. https://doi.org/10.1590/1413-812320141911.10692014

Avelar, M.R. \& Malfitano, A.P.S. Entre o suporte e o controle: a articulação intersetorial de redes de serviços. Ciênc. saúde coletiva [online]. 2018, vol. 23, no. 10 .

Behring, E. R., \& Boschetti, I. (2011). Política social: Fundamentos e história. Cortez.

Bravo, Maria Ines Souza. (2006). Políticas de Saúde no Brasil. In MOTA, Ana Elizabete. [El al], (orgs). Serviço Social e Saúde - Formação e Trabalho Profissional (p. 88-100).

Bravo, Maria Inês Souza. (2013). Prefácio. In SILVA, L. B.; RAMOS, A (Org). Serviço Social, Saúde e Questões Contemporâneas: Reflexões Críticas Sobre a Prática Profissional.

Bravo, Maria Ines Souza, Pelaez, E. J., \& Pinheiro, W. N. (2018). As contrarreformas na política de saúde do governo Temer. Argumentum, 10(1), 6-23. https://doi.org/10.18315/argumentum.v10i1.19139

Carmo, M. E. do, \& Guizardi, F. L. (2017). Desafios da intersetorialidade nas políticas públicas de saúde e assistência social: Uma revisão do estado da arte. Physis: Revista de Saúde Coletiva, 27(4), 1265-1286. https://doi.org/10.1590/s0103-73312017000400021

Carvalho, M. S. N. de. (2019). Desospitalização de crianças com condições crônicas complexas: Perspectivas e desafios (L. A. de M. Menezes, A. D. da C. Filho, \& C. M. de P. Maciel, Orgs.; $1^{\circ}$ ed). Editora Valentina.

Castro, M. M. C., Oliveira, A. S. O., \& Resende, L. T. ([s.d.]). Humanização em saúde e Serviço Social: Estado da arte, reflexões e desafios. In FORTI, V.; GUERRA, Y. (orgs.). Serviço Social e Política de Saúde - Ensaios sobre trabalho e formação profissionais. Lumen Juris.

Cecílio, L. C. de O. (2001). As necessidades de saúde como conceito estruturante na luta pela integralidade e equidade na atenção em saúde. In Pinheiro R, Mattos R. A. Os sentidos da integralidade na atenção e no cuidado à saúde. UERJ.

Cecílio, L. C. de O., \& Merhy, E. E. (2007). A Integralidade do Cuidado como Eixo da Gestão Hospitalar. In Pinheiro, R; Mattos, R. A. (orgs) Construção da Integralidade: cotidiano, saberes e práticas em saúde. UERJ, IMS: ABRASCO.

Cislaghi, J. F. (2018). Privatização da gestão na saúde e precarização do trabalho no Brasil. In Ramos, A.; Silva, L.B.; Paula, L.G.P. (orgs). Serviço Social e Política de Saúde - ensaios sobre trabalho e formação profissionais. Lumen Juris.

Costa, M. D. H. da. (2010). Serviço social e intersetorialidade: A contribuição dos assistentes sociais para a construção da intersetorialidade no cotidiano do Sistema Único de Saúde [Dotourado]. UFPE.

Cunha, M. A. O., \& Morais, H. M. M. de. (2007). A assistência domiciliar privada em saúde e suas estratégias (aparentes e ocultas). Ciência \&amp; Saúde Coletiva, 12(6), 1651-1660. https://doi.org/10.1590/S1413-81232007000600026

Dighiero, K. B. (2015). Las políticas y el cuidado en América Latina Una mirada a las experiencias regionales. CEPAL.

Ervatti, L., Borges, G. M., Jardim, A. de P., \& Instituto Brasileiro de Geografia e Estatística (Orgs.). (2015). Mudança demográfica no Brasil no início do século XXI: Subsídios para as projeções da população. IBGE, Instituto Brasileiro de Geografia e Estatística.

ESCOREL, S. Equidade em saúde. In: PEREIRA, I. B.; LIMA, J. C. F. Dicionário da educação profissional em saúde. 2. ed. Rio de Janeiro: Escola Politécnica em Saúde Joaquim Venâncio, 2009. Disponível em: \&amp;1t; http://www.epsjv.fiocruz.br/dicionario/verbetes/equsau.html\&amp;gt;.

Franco, C. M., Santos, S. A., \& Salgado, M. F. (2011). Manual do Gerente: Desafios da média gerência na saúde (L. R. Pessôa, E. H. de A. Santos, \& K. R. B. de O. Torres, Orgs.). ENSP.

Guará, I. M. F. R. G., \& Gonçalves, A. S. (2010). Redes de proteção social na comunidade. In Guará I. M. F. R. (org). Redes de proteção social. Associação Fazendo História.

Junqueira, L. A. P. (2000). Intersetorialidade, transetorialidade e redes sociais na saúde. Revista de Administração Pública, 34(6): 35-45.

Instituto Brasileiro de Geografia e Estatística. Mudança Demográfica no Brasil no Início do Século XXI: subsídios para as projeções da população. 2015.

Leite, R.F.B., \& Veloso, T.M.G. Psicologia Ciência e Profissão, 2008, 28 (2), 374-389

Malta, D.C; Goshi, C. S; Buss, P; Rocha D.G.; Rezende, R; Freitas, P. C;Akerman, M. Doenças Crônicas Não Transmissíveis e o suporte das ações intersetoriais no seu enfrentamento. Ciência \&amp; Saúde Coletiva,19(11):4341-4350, 2014.

Marcondes, M. M. (2013). A corresponsabilização do estado pelo cuidado: Uma análise sobre a Política de Creches do PAC-2 na perspectiva da divisão sexual do trabalho [Dissertação de mestrado]. 
Martinho, C. (2003). Redes: Uma introdução às dinâmicas da conectividade e da auto-organização. WWF-Brasil.

Matos, M.C. Serviço Social Ética e Saúde - reflexões para o exercício profissional. 2ed São Paulo: Cortez, 2017.

Mendes, E. V. (2012). O cuidado das condições crônicas na atenção primária à saúde: O imperativo da consolidação da estratégia da saúde da família. OPAS.

PORTARIA N $N^{\circ}$ 3.390, DE 30 DE DEZEMBRO DE 2013, (2016). Institui a Política Nacional de Atenção Hospitalar (PNHOSP) no âmbito do Sistema Único de Saúde (SUS), estabelecendo- se as diretrizes para a organização do componente hospitalar da Rede de Atenção à Saúde (RAS). http://bvsms.saude.gov.br/bvs/saudelegis/gm/2013/prt3390_30_12_2013.html

Mioto, R. C. (2010). Família, trabalho com famílias e Serviço Social. Serviço Social em Revista, 12(2), 163. https://doi.org/10.5433/1679-4842.2010v12n2p163

Minayo, M.C.S. Ciência, técnica e arte: o desafio da pesquisa social. In: Pesquisa Social. Teoria, método e criatividade. DESLANDES, SF et. al (orgs). 21 ed. Petrópolis: Vozes, 2002.

Monnerat, G. L., \& Souza, R. G. (2014). Intersetorialidade e Políticas Sociais: Um diálogo com a literatura atual. In MONNERAT, G.L. (orgs) A intersetorialidade na agenda das políticas sociais. Papel Social.

Moreira, M. E. L., \& Goldani, M. Z. (2010). A criança é o pai do homem: Novos desafios para a área de saúde da criança. Ciência \&amp; Saúde Coletiva, 15(2), 321-327. https://doi.org/10.1590/S1413-81232010000200002

Netto, J. P. (1992). Capitalismo Monopolista e Serviço Social. Cortez Editora e Livraria Ltda. http://public.eblib.com/choice/PublicFullRecord.aspx?p=6432564

Nogueira, A.C \& Monteiro, M.V. A família e a atenção em saúde: proteção, participação ou responsabilização? In: SILVA, Letícia Batista; RAMOS, Adriana (Org.). Serviço social, Saúde e questões contemporâneas: reflexões críticas sobre a prática profissional. Campinas, SP: Papel Social, 2014.

Nunes, N. R. de A., Rocha, D. G., \& Fernandes, F. L. (2019). O Direito a Saúde em Tempos de Austeridade: Limites, desafios e possibilidades. O Social em Questão, 44, 09-20.

Otávio Cruz Neto. (2002). O trabalho de campo como descoberta e criação. In In: DESLANDES, SF et. Al (orgs). Pesquisa Social. Teoria, método e criatividade. Vozes.

Organização Mundial da Saúde. (1946). Constituição da Organização Mundial da Saúde.

OXFAM Brasil. (2018). País estagnado: Um retrato das desigualdades brasileiras.

Passos, R. G. (2018). Teorias e Filosofias do Cuidado - subsídios para o Serviço Social. Papel Social.

Passos, R. G. (2018). "Entre o assistir e o cuidar": Tendências teóricas no Serviço Social brasileiro. Revista Em Pauta, 15(40), 247-260. https://doi.org/10.12957/rep.2017.32725

Rocha, P. R. da, \& David, H. M. S. L. (2015). Determinação ou Determinantes? Uma discussão com base na Teoria da Produção Social da Saúde. Revista da Escola de Enfermagem da USP, 49(1), 129-135. https://doi.org/10.1590/S0080-623420150000100017

Rocha, L. T. (2016). Hospital não, pelo amor: Etnografando processos de desospitalização. Instituto de Medicina Social -UERJ.

Silva, K. L., Sena, R. R. de, \& Castro, W. S. (2018). A desospitalização em um hospital público geral de Minas Gerais: Desafios e possibilidades. Revista Gaúcha de Enfermagem, 38(4). https://doi.org/10.1590/1983-1447.2017.04.67762

Desospitalização: sistema de saúde está refém dos hospitais de alta complexidade, indicados apenas para o tratamento de doenças agudas. (2018). Visão Saúde, 7 .

Soares, L. T. (2000). As atuais políticas de saúde: Os riscos do desmonte neoliberal. Revista Brasileira de Enfermagem, 53(spe), 17-24. https://doi.org/10.1590/S0034-71672000000700003

Vasconcelos, A. M. de. (2017). A/O Assistente Social na luta de classes: Projeto profissional e mediações teórico-práticas. Cortez. http://search.ebscohost.com/login.aspx?direct=true \&scope=site \&db=nlebk\&db=nlabk\&AN=2244614

Vecina Neto, G., \& Malik, A. M. (2007). Tendências na assistência hospitalar. Ciência \& Saúde Coletiva, 12(4), 825-839. https://doi.org/10.1590/S141381232007000400002

Vieira, F. S., \& Benevides, R. P. de S. (2016). Os Impactos do novo regime fiscal para o financiamento do Sistema Único de Saúde e para a efetivação do direito à saúde no Brasil (Nota Técnica N $\mathrm{N}^{\mathrm{O}}$ 28). IPEA.

Wiese, M. L., Dal Prá, K. R., \& Mioto, R. C. T. (2017). O cuidado como direito social e como questão de política pública. Seminário Internacional Fazendo Gênero 11 \& 13th Women's Worlds Congress.

World Health Organization (Org.). (2002). Innovative care for chronic conditions: Building blocks for action: global report. World Health Organization. Yazbek, M. C. (2014). Sistemas de proteção social, Intersetorialidade e Integração de Políticas Sociais. In In: MONNERAT, G. L. (orgs). A intersetorialidade na agenda das políticas sociais. Papel Social. 